\title{
Open Government Data from the Perspective of Information Needs: A Tentative Conceptual Model
}

J onathan Crusoe, Elisabeth Gebka and Karin Ahlin

The self-archived postprint version of this journal article is available at Linköping University Institutional Repository (DiVA):

http:/ / urn.kb.se/ resolve?urn=urn:nbn:se:liu:diva-169070

N.B.: When citing this work, cite the original publication.

The original publication is available at www.springerlink.com:

Crusoe, J ., Gebka, E., Ahlin, K., (2020), Open Government Data from the Perspective of Information Needs: A Tentative Conceptual Model, Electronic Government, , 250261. https:// doi.org/ 10.1007/978-3-030-57599-1_19

Original publication available at:

https:// doi.org/ 10.1007/978-3-030-57599-1 19

Copyright: Springer Verlag

http:// www.springerlink.com/ ?MUD=MP 


\title{
Open Government Data from the Perspective of Information Needs - A Tentative Conceptual Model
}

\author{
Jonathan Crusoe $\mathrm{e}^{1[0000-0003-4740-1242]}(\varangle)$, Elisabeth \\ Gebka $^{2[0000-0002-1577-9956]}$, and Karin Ahlin3 [0000-0003-4051-6960] \\ 1 Division of Information Systems, Linköping University, 58183 Linköping, Sweden \\ jonathan.crusoe@liu.se \\ 2 Creativity and Innovation Research Center, University of Namur, Belgium \\ elisabeth.gebka@unamur.be \\ 3 Department of Computer and System Science, Mid Sweden University, 83136 \\ Östersund, Sweden \\ karin.ahlin@miun.se
}

\begin{abstract}
Information seekers can use products and services based on open government data (OGD) to satisfy their information needs. These solutions are provided by data transformers reusing OGD shared by publishers. OGD is believed to lead to several benefits, such as transparency and innovation. However, there is a noted lack of OGD use, and little seems to be known about the need for OGD. Therefore, we developed a tentative conceptual model, from which data transformers and publishers can understand and consider the information needs of information seekers. We used design science research to develop the model based on previous research and empirical material from workshops. We conducted workshops in Belgium with nine researchers and eleven students and presented the model at a Scandinavian e-government workshop. The findings from the study show that information needs are complex and can be challenging to capture, but are one possible way to understand how the benefits of OGD could be realized. One practical implication is that publishers and data transformers should identify information needs in society, study existing solutions, and attempt to go beyond them with OGD. The synthesized theoretical implication is that information needs might help to guide on the role of OGD in society.
\end{abstract}

Keywords: Open Government Data · Information Seeker · Information Need · Conceptual Model

\section{Introduction}

In previous open government data (OGD) research, little seems to be known about the relationships between information seekers, data transformers, and publishers. This gap leaves it unclear why OGD would be integrated into the rest of society. This article presents a tentative conceptual model from which data 
transformers and publishers can understand and consider the information needs of information seekers. Information needs arise when people experience a gap in their knowledge [3]. These needs can be satisfied when people make sense out of data [15]. One source of data is OGD which is shared by public organisations (publishers) for anyone to be freely reused [1]. OGD can be used directly or integrated into services and products (solutions) by data transformers for information seekers to satisfy their information needs [9]. Data transformers can, for example, be developers, journalists, or researchers [22], while information seekers are people that seek information to satisfy their information needs.

Publishers, data transformers, and information seekers can experience problems. Publishers may lose income or data transformers may be unable to find data [25], while information seekers can have unexpressed or unrecognised information needs [11]. Previous research tends to focus on the publisher and data transformer, while the information seeker is in the background or a type of data transformer [e.g., 10, 16, 26]. This placement needs to change since the public interest in the re-use of OGD has been declared a myth [14]. The myth may come from that current information needs are already satisfied by other solutions [20]. The satisfaction of information needs may be the event where data and information, through use, impact information seekers' lives to realize the promised benefits of OGD.

The purpose of this article is two-fold: (1) create an initial understanding of information needs in relation to OGD and (2) suggest possible considerations for data transformers and publishers, both presented in a conceptual model. A conceptual model is a set of assumptions that supports and informs the research and is a key part of the design [19]. The model can help data transformers and publishers understand how OGD and OGD solutions can be of value to information seekers. On the other hand, researchers can use the model as a basis for future research on how to increase the use of OGD or how OGD can have an impact on society. In this paper, we focus on everyday activity-based information needs, such as finding your way to work or keep up-to-date on your urban surroundings. The following research question guides the research: what may data transformers and publishers need to consider about information needs of information seekers in an everyday context?

This paper starts by presenting the background, then the research process, and the conceptual model followed by a discussion. This paper ends with a conclusion.

\section{Background}

This section explains the concept of information needs and information solutions.

\subsection{Information Needs of Information Seeker}

People experience information needs when they experience a gap in their knowledge [3], which can happen when they attempt to satisfy a primary need [24]. 
If the situation is unclear, confusing, or difficult to understand the information seeker might be unable to formulate questions (identify information needs) that can help them identify the right information [8]. Information needs are determined by individual's social role, environment, and previous knowledge [24] and satisfying them can help people work effectively, solve a problem satisfactorily, or pursue a hobby [20]. Information seekers' information needs can be complex. For example, in a modern city environment the urban system is a vast system of systems where information seekers can have different roles based on what functions of the city they are using, such as a citizen, professional, or commuter [12]. In each role, they have different information needs. OGD can be socially valuable when understandable and usable by the intended people or communities. OGD should fit the preferences, level of expertise, and personal needs of the information seekers [4]. Visualizations are one important tool to achieve these requirements [2].

People can use information for: (1) fact-finding - getting hold of answers to specific questions, (2) staying aware - keeping up to date on something, (3) researching - investigating a new field in depth, (4) briefing - obtaining background understanding of an issue or topic, (5) stimulus - procuring ideas or stimuli, and (6) recreation - looking for interesting tidbits of information just for the fun of it [20]. At the same time, individuals, experiences, and situations are sources of information and knowledge, and information can be found in unexpected ways and places [11]. In the digital world, information seekers are creative and able to choose from a large offer of information sources and even influence information solutions. The information providers have to consider them as clients to meet their needs properly, at the risk of seeing them choosing other solutions [20].

\subsection{Information Solutions from Data Transformers and Publishers}

An information solution is a product or service that supports the sense making of information from data or presents information or data to the information seeker. Here, we focus on digital solutions, which seem to be well-suited to satisfy information needs [17]. In the case of OGD, a published dataset is considered an information solution. The publisher is assumed to be a public organisation that releases data. On the abstract level, the release process for data starts with collecting data, then preparing data, publishing data, maintaining data, engaging data transformers, and ends with collecting feedback $[1,5,26]$. The result of the process is OGD that can be used by data transformers or information seekers. Data transformers can transform the data into facts, information, interfaces, new datasets, or services [9], which can cover a wide variety of roles and business models for the data transformers [16]. The solutions should be specifically fit to their intended purpose or function [20]. The products can, for example, be reports, visualisations, simulations, and news articles, while services can be a web service that notifies information seekers about interesting events [7]. On the other hand, information seekers can read some facts in a dataset and be satisfied [9]. 


\section{Research Process}

This research is using design science research (DSR) to build a tentative conceptual model that is a new artifact. The conceptual model is directed toward solving a practical problem. This research followed the steps of DSR [21]: (1) problem identification and motivation, (2) definition of the objectives for a solution, (3) design and development, (4) demonstration, (5) evaluation, and (6) communication. The steps 2 to 5 were done in iterations. A previous version of the model was communicated at the 17th Scandinavian Workshop on E-Government. Here, we want to note that this paper has a sibling paper also presented at the workshop and accepted as ongoing research to the EGOV-CeDEM-ePart 2020 conference, which developed the data collection workshop [see 13].

\subsection{Problem Identification and Motivation}

This research was initiated when reflecting on the possible sources of the noted lack of use [22] to then wonder about the need for OGD solutions. This reflection prompted a traditional literature review to identify previous research [6]. This literature review is presented in the background section. Google scholar was used as the search engine, as it has a good coverage and recall and we used simple keywords, which the search engine has a prevision above average with [23]. Examples of used keywords are "open data", "information needs", "open data information needs", and "citizens information needs".

The design problem of this research is how to conceptualise the connection between information seekers' information needs, data transformers' solutions, and publishers' OGD to gain insight into how OGD and OGD solutions could be valuable to information seekers. Also, to identify considerations to data transformers and publishers to ensure this value. The theoretical motivation of the problem continues on previous research on information needs and OGD by combining both. The practical motivation is a perceived need to increase the use of OGD, which is believed to lead to several benefits. An important aspect of the development of the model was to use an information seeker perspective, which takes into account the publisher's and data transformer's role for the solutions.

\subsection{Iterations}

The iterations consist of step 2 to 5 of DSR [21]. For the first iteration, the purpose was to explore information needs. Two of the three researchers observed an information-rich bus-hub in a medium-sized Swedish town, conducted six structured-interviews with available commuters, and one in-depth interview with a veteran commuter. They were asked about activities and needed information. The empirical material was discussed between the two researchers and the insights were then used to design a workshop method [13], as observations and interviews gave insufficient results or were too time-consuming. 
The workshop method. The workshop method [13] was used one time in the second iteration and one time in the third iteration. For the participants of the workshops to recognise information needs, they needed to face a situation where they experience knowledge gaps but are not so unfamiliar they cannot formulate questions. To simulate this situation, a scenario was developed and used in a collaborative workshop, since participatory approach can help participants identify information needs [2]. The selected scenario was "moved into a new city but not settled" (which in the first iteration generated the richest data about activity-based information needs in an everyday context). The second iteration allowed the participants to freely suggest categories of activities and information needs in the scenario context. However, it slowed down the discussions and idea generation as their focus was on clarifying the situation. The third iteration consisted of pre-defined options of activity domains, selected from the occurrences of the second iteration based on perceived commonness. At both workshops, participants, alternately alone and in small teams of 2 to 4, wrote down activities with the needed information, possible existing solutions, and brainstormed new dream solutions on specific cards. Finally, the result was presented and discussed together. In total, two workshops were conducted: the first with nine Belgian researchers and the second with eleven Belgian students. The Belgian participants came from the University of Namur. The university is part of the city of Namur, which is the regional capital of Wallonia. The city has 110,939 inhabitants, a dominant service industry (e.g., commercial activities and the university), and publishes OGD. Table 1 presents a summary of the empirical material.

Analysis of the results. Cards from the groups were grouped, skimmed, and prioritised based on their size and clearness on information needs (smallest and clearest first). This approach was chosen as it allowed the conceptual model to grow slowly and steadily. One at a time, the card groups were discussed and analysed by two of the researchers conducting this study based on the concepts presented in the background section. This process involved writing the data from the cards to a memo where analytical notes were added through discussion and analysis. The conceptual model was constructed through constant comparison between the current group and the model, which allowed for the identification of the theoretical concepts in the empirical material. This process helped to demonstrate and evaluate the model in small steps. Once the two workshop iterations had been executed, the memos and model were analysed by one of the researchers conducting this study and condensed to one memo, which was further refined to a new memo representing a new model. The process was then presented and discussed with one of the researchers of this study. Afterwards, the model was conceptualised and studied to identify gaps. The model was then reviewed by the remaining two researchers conducting this study based on [18]: fidelity with real-world phenomena, completeness, level of detail, robustness, and internal consistency. Finally, the model was submitted to a Scandinavian e-government workshop and received final touches based on feedback and recommended research. Previous research has supported the development of the data collection, guided the analysis, and became a part of the conceptual model. The concepts 
Table 1. Summary of the empirical material from the workshops

\begin{tabular}{|c|c|c|c|}
\hline & Participant Background & Primary needs & Information needs \\
\hline \multirow{3}{*}{$\begin{array}{l}\text { Workshop } 1 \\
\text { Activities } \\
\text { (Primary needs) } \\
\text { open to suggestions }\end{array}$} & \begin{tabular}{|l} 
Researchers in \\
Group 1 Information Management (1), \\
Computer Science (2), \\
and Business Informatics (1)
\end{tabular} & $\begin{array}{l}\text { Move to the city } \\
\text { Discover the city } \\
\text { Make friends } \\
\text { Find store }\end{array}$ & $\begin{array}{l}\text { Public transport } \\
\text { List: description and accessibility of } \\
\text { events, and available products } \\
\text { Points of interest } \\
\text { Recommendations for finding friends }\end{array}$ \\
\hline & \begin{tabular}{|l} 
\\
Researchers in \\
Group 2 2 Macation (1), \\
Management and Creativity (1), \\
Management (1)
\end{tabular} & $\begin{array}{l}\text { Find friends } \\
\text { Find services (doctors, } \\
\text { sport, shops) } \\
\text { Environment }\end{array}$ & $\begin{array}{l}\text { Descriptions: facilities, location, } \\
\text { prices, timetables, soft skills, } \\
\text { and atmosphere of the places } \\
\text { Like-minded people } \\
\text { Peer recommendations }\end{array}$ \\
\hline & \begin{tabular}{|c} 
Researchers in \\
Group 3 Education and Management (1) \\
Media Industry (1)
\end{tabular} & $\begin{array}{l}\text { Get dressed } \\
\text { Leisure, shopping, } \\
\text { services, and schools } \\
\text { Local integration, } \\
\text { safety, and health }\end{array}$ & $\begin{array}{l}\text { Weather, fashion, streets } \\
\text { Descriptions: facilities, location, } \\
\text { prices, timetables, and attendees } \\
\text { Local food, stereotypes } \\
\text { Best schools, doctors, and service providers } \\
\text { Peer recommendations and tacit rules } \\
\text { Like-minded people }\end{array}$ \\
\hline \multirow{3}{*}{$\begin{array}{l}\text { Workshop } 2 \\
\text { Activities } \\
\text { (Primary needs) } \\
\text { from suggested } \\
\text { categories }\end{array}$} & Group $4 \begin{array}{l}\text { Students in } \\
\text { Management (3) }\end{array}$ & $\begin{array}{l}\text { Eat and Drink: } \\
\text { restaurants, shops } \\
\text { bars, and delivery } \\
\text { services }\end{array}$ & $\begin{array}{l}\text { Descriptions: facilities, location, } \\
\text { prices and payment, timetables, } \\
\text { delays, attendees, and } \\
\text { occupation rate per hours } \\
\text { Peer recommendations and trustful reviews }\end{array}$ \\
\hline & $\begin{array}{|ll|}\text { Students in } \\
\text { Informatics (1) } \\
\text { Group } 5 \text { Political sciences (1) } \\
\text { Project Management (1) } \\
\text { Unspecified (1) }\end{array}$ & $\begin{array}{l}\text { Socialize and } \\
\text { make friends }\end{array}$ & $\begin{array}{l}\text { Places to go out } \\
\text { Like-minded people } \\
\text { Associations and activities } \\
\text { on the campus }\end{array}$ \\
\hline & Group $6 \begin{array}{l}\text { Students in Analytics } \\
\text { and Digital business (4) }\end{array}$ & $\begin{array}{l}\text { Socialize and } \\
\text { make friends }\end{array}$ & $\begin{array}{l}\text { Services and activities, carpooling with friends, } \\
\text { and accommodation with friends } \\
\text { Descriptions: location, schedules, prices, } \\
\text { accessibility, and conditions } \\
\text { Attendees in working groups, travels, } \\
\text { music bands, and parties }\end{array}$ \\
\hline
\end{tabular}

and considerations were interpreted from previous research and the empirical material, where the first provided a skeleton, which the second added to.

\section{A Tentative Conceptual Model}

In this section, we present a tentative conceptual model (see Figure 1). As the concepts are presented in the text below, examples from group 1, group 3 , and group 4 are given. These groups were selected based on the perceived clearness of information needs and completeness and size of their descriptions. The presentation will follow information seeker, then data transformer, and, finally, publisher.

\subsection{Information Seeker}

The model starts with the information seekers trying to satisfy a primary need, which is the basic incentive to move and undertake any activity. However, they encounter a perceivable gap in their knowledge to perform the desired activity $[3,8,24]$. If the gap is filled, it can help them satisfy their primary need through the activity. The activity domain chosen by group 1 was to make new friends or socialise by participating in the local life (primary need of love and belonging), 


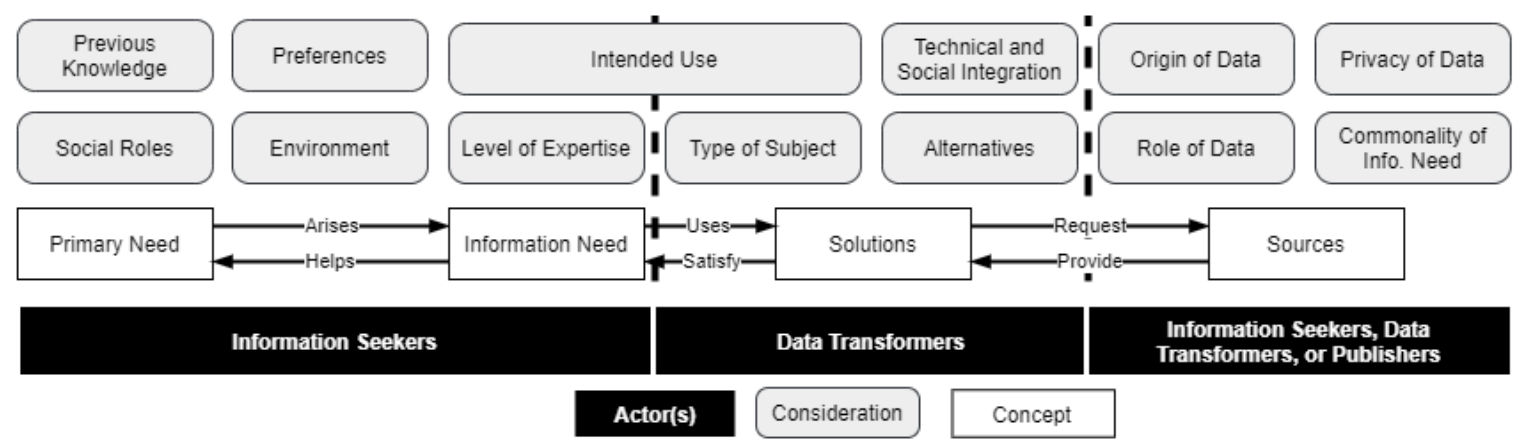

Fig. 1. The tentative model of information needs, solutions, and sources.

group 3 was to go to shops (physiological needs), and group 4 sought to eat and drink in the city (physiological needs and sense of belonging). However, in the given scenario (settling down in a new town), they lacked information.

The information seekers recognize their knowledge gap and an information need arises. They start to search for solutions that they can use to satisfy their information need. This need takes the form of unformulated questions (gaps) with specific requests for data $[3,8,20]$. Group 1 explained that they wanted descriptions and accessibility of events and products, but also possible friends. The information should contain recommendations, a list of social activities and groups, points of interest, prices, profiles of people attending, and schedules. Group 3 sought information about the weather, fashion, street descriptions, and shops. Group 4 saw four ways to approach their primary needs. First, look for a bar. Second, food delivery services. Third, look for where to purchase groceries. Fourth, look for restaurants. They also wanted ratings with the four approaches. In common, the groups tended to omit important data, such as locations for weather and opening hours for businesses.

The expression of an information need coalesce (grow together to form one thing) with different factors, which should be considered by data transformers and publishers. The information seeker's previous knowledge about a topic, preferences, intended information use, social roles, environment, and level of expertise coalesce with the information need to become the expression of their information need [4, 12, 20, 24]. These requirements should be met to enable good satisfaction of the primary need [20]. Group 1 explained that new friends should have similar interests or needs, while the activities should be similar to their interests, reoccurring, prioritised, and in a certain format (e.g., parties and pubs). Group 3 wanted to quickly reach their destination in fresh and comfortable condition. Group 4 wanted the services to be rated by other customers to gain more transparency and trust from the provided information.

As a result, it can be interpreted that the participants seek reliable and useful information. Both social groups (researchers and students) value the trans- 
parency carried by peer reviews and their community, since the information source is not always clearly identified in a final solution, whatever the data comes from (OGD or businesses). The usefulness perception of the information is constrained by the personal considerations (e.g. preferences, previous knowledge, social role). For instance, for the food and restaurants activities, both groups mentioned categories of information such as price, location, and available products or menus. However, what is really valued and will make the difference is the personal consideration about the information (what is "expensive" for the information seeker, what makes a restaurant "good"). This evaluation of the information is better supported by the community ratings than by the transparency feature of OGD.

\subsection{Data Transformer}

Data transformers develop solutions that they provide to information seekers. A solution provides information and data that can answer questions and fill knowledge gaps [7, 9, 20]. Group 1 saw two possible solutions to their information need. First, Tinder4Friends is an application that suggests activities where they can find friends based on the information seeker's profile. Second, Place2Be is a website that describes where to be every day and night based on the information seekers' profiles and interests. The locations can be shared on social media to organise the activity with their friends. Group 3 suggested two solutions: (1) Mode-Fashion is an online catalog that in real-time provides the latest fashion and (2) Streets is a pedestrian navigation application (using a routing algorithm) based on community contribution that helps the information seeker navigate to shops. The community adds data about the state of streets, parking, pollution, snow levels, and the number of steps on the way. Group 4 suggested that every bar or restaurant has a happy and a sad button that customers can press to rate the service. The ratings are then published on a website or in an open database.

The data transformers have some possible considerations. First, how the solutions are designed for its intended use [12, 24]. Tinder4Friends and Place2Be help to brief the information seeker about people or events in an area. ModeFashion helps the information seeker to stay aware on a topic. Streets helps the information seeker to find facts (a route between two locations). On the other hand, the button with its website could allow the seeker to brief or find facts depending on the implementation. "Brief" if it allows the seeker to see all options together. "Find facts" if the seeker can only ask for one restaurant at a time. Second, the type of subject in the solution [20] can be based on topics (e.g., fashion), problems (e.g., navigation), or events (e.g., parties). Third, how the solution is integrated with other solutions (e.g., social media) and the information seeker communities (e.g., in the Streets, the community contributes with data, while in Place2Be users find each other through common events). Fourth, alternatives to the solution [20]. Tinder4Friends and Place2Be satisfy the same need with a slight variation which could make them compete if developed. On the other hand, Mode-Fashion and Streets together help to satisfy an information need, which means they collaborate. 
In sum, the respondents expressed their demand for efficient information solutions that can satisfy several information needs at a time, in one place. They value the quality standards and functionalities they know from other solutions, but more than everything, they value the fact they can find all information at once, save time, energy, with trust.

\subsection{Publisher}

The conceptual model focuses on the information seeker, while giving some attention to the publisher, who provides data requested by solutions. Data sources can originate from information seekers, data transformers, publishers, or a mix of them. The data transformers and publishers have some possible considerations. First, the origin of the data [16, 20]. The data transformer can provide data through the solution, or the information seeker can add data to the solution. The data provided can either be OGD from publishers or data from other sources, such as shops or restaurants. Second, the privacy of the data. Added data can range from private data (not shared) to public data (shared with other information seekers). Third, the role of the data. Provided data can act as a base or skeleton for other data, while added data can help to evaluate (e.g., ratings of restaurants). Origin, privacy, and role of data can be mixed in one solution. Streets could use locations from publishers, state and pollution of streets from information seekers, and private location data from an information seeker to calculate a route. Third, the commonality of the information needs of a group, community, or society [20]. The solutions and related data have a window of possible uses. The dream solution Streets is for traveling or planning to travel, Mode-Fashion is for when the information seeker wants to refresh their knowledge about fashion, and Place2Be when he seeks something to do with friends.

In sum, what matters for the information seekers is how a given solution meets their information needs. For that, many sources might be required to provide relevant data and offer a comprehensive solution. The real value proposition of the solution depends on the match between the solution and its user's information needs. In the activity-based scenario of this study, the solution never depends on one single publisher, regardless the quality of its data.

\section{Discussion}

Information needs are complex and not easy to capture. One described example of this is that there is a tendency to omit important data (e.g., geographical data for weather). This behaviour could be a form of unrecognised information need [11], but likely the data is perceived to be commonly understood by the participants. Following that the information seekers do not fully deal with the underlying datasets is that data transformers and publishers have to take care about information seekers' information needs. They have to match the information seekers and their information needs with their solutions and data [e.g., 7, 9]. Therefore, OGD does not follow a one-directional flow. Rather, two sides of need 
and data meet in one solution. The data transformer has to ensure that the two sides mix properly, while he has little ability to control both.

\section{$5.1 \quad$ Implications}

We have also identified some implications for practice and future research. The practical implications are directed to publishers and data transformers of OGD. The model has taught us that before publishers provide OGD or data transformers develop solutions, they should identify information needs in their society, study existing solutions, and come up with ways to go beyond them. Data transformers should consider the content of their solution to ensure it can be used to answer questions that can come from several knowledge gaps. They are also recommended to think about how data is mixed from different sources and what data will be provided or added for the perceived value it adds to the solution for the information seeker (e.g., trust, reliability). On the other hand, publishers should consider how their data can be combined with other data of similar type (e.g., environmental or transportation) or relatedness (e.g., roads and weather). Identifying information needs and the possible answers could help reveal the relatedness. The theoretical implications are aimed towards OGD and e-government researchers. OGD tended to be painted as a supply or demand issue [e.g., 10]. Our model expands on this idea as it focuses on information needs that arise when there is a gap in the knowledge of the individual, while information demands are requests for information that are believed to be needed [20]. Based on the tentative model, there are some suggestions. The information seeker's role in OGD can be considered in relation to information needs in society. Previous research about information needs may be able to help, support, and guide future OGD research.

\subsection{Limitations and future work}

The above model can be generalised to primary needs and information needs that are activity-based in an everyday context where it is easy to formulate questions. The scenario was general enough to be experienced beyond researchers and students in Belgium, but focused on the "fact-find", "brief", and "stay aware" use of solutions. Future research is needed about situations with researchbased, stimulation-based, and recreational-based information use. The literature review aimed at gaining insight into an issue, and the resulting background could be further developed with a systematic literature review, but we believe it has captured relevant research for this study. The current model is based on the perspective of the information seeker and should be extended with the perspective of publishers and data transformers. At the same time, it needs further testing in other contexts. Further research is needed about how to bridge the gap between publishers and information seekers through the development and use of solutions. The combination of information needs and benefits of OGD is one possible direction. The connection between providing and adding data in a solution is one interesting gap that can be explored further. 


\section{Conclusion}

The contribution of this paper is two-fold: a tentative conceptual model and possible considerations (see Figure 1). The model is one way to understand how OGD can be integrated into society by satisfying information needs. The use of data and information in solutions can impact information seekers' lives to realize the benefits of OGD. However, information needs come in many shapes and forms, are complex, and not always fully expressed, which can make them challenging to capture. Data transformers and publishers can view the information in a solution as a data concoction brought together from different sources rather than a one-way data flow. The model presents the complexity of connecting the needs of information seekers with data provided by publishers through a solution changeable by data transformers.

\section{Bibliography}

[1] Attard, J., Orlandi, F., Scerri, S., Auer, S.: A systematic review of open government data initiatives. Government Information Quarterly 32(4), 399418 (2015)

[2] Barbosa Tavares, R., Hepworth, M., De Souza Costa, S.M.: Investigating citizens' information needs through participative research: a pilot study in candangolândia, brazil. Information Development 27(2), 125-138 (2011)

[3] Belkin, N.J., Vickery, A.: Interaction in information systems: A review of research from document retrieval to knowledge-based systems. No. 025.04 BEL. CIMMYT. (1985)

[4] Cabitza, F., Locoro, A., Batini, C.: Making open data more personal through a social value perspective: a methodological approach. Information Systems Frontiers pp. 1-18 (2018)

[5] Carrara, W., Oudkerk, F., Van Steenbergen, E., Tinholt, D.: Open data goldbook for data managers and data holders (2018)

[6] Cronin, P., Ryan, F., Coughlan, M.: Undertaking a literature review: a stepby-step approach. British journal of nursing 17(1), 38-43 (2008)

[7] Crusoe, J.R., Ahlin, K.: Users' activities for using open government data-a process framework. Transforming Government: People, Process and Policy (2019)

[8] Daft, R.L., Lengel, R.H.: Organizational information requirements, media richness and structural design. Management science 32(5), 554-571 (1986)

[9] Davies, T.: Open data, democracy and public sector reform. A look at open government data use from data.gov.uk pp. 1-47 (2010)

[10] Dawes, S.S., Vidiasova, L., Parkhimovich, O.: Planning and designing open government data programs: An ecosystem approach. Government Information Quarterly 33(1), 15-27 (2016)

[11] Erdelez, S.: Information encountering: It's more than just bumping into information. Bulletin of the American Society for Information Science and Technology 25(3), 26-29 (1999) 
[12] Fernández-Güell, J.M., Collado-Lara, M., Guzmán-Araña, S., FernándezAñez, V.: Incorporating a systemic and foresight approach into smart city initiatives: the case of spanish cities. Journal of Urban Technology 23(3), 43-67 (2016)

[13] Gebka, E., Crusoe, J., Ahlin, K.: Open data reuse and information needs satisfaction: a method to bridge the gap. In: Proceedings of CEUR EGOVCeDEM-ePart (2020), ongoing Research; Accepted; Not Published

[14] Hellberg, A.S., Hedström, K.: The story of the sixth myth of open data and open government. Transforming Government: People, Process and Policy $\mathbf{9}(1), 35-51(2015)$

[15] Hey, J.: The data, information, knowledge, wisdom chain: the metaphorical link. Intergovernmental Oceanographic Commission 26, 1-18 (2004)

[16] Lindman, J., Kinnari, T., Rossi, M.: Business roles in the emerging opendata ecosystem. IEEE Software 33(5), 54-59 (2016)

[17] Madsen, C.Ø., Hofmann, S., Pieterson, W.: Channel choice complications - exploring the multiplex nature of citizens' channel choices. In: Electronic Eovernment: 18th IFIP WG 8.5 International Conference, EGOV 2019, San Benedetto Del Tronto, Italy, September 2-4, 2019, Proceedings. vol. 11685, p. 139. Springer (2019)

[18] March, S.T., Smith, G.F.: Design and natural science research on information technology. Decision support systems 15(4), 251-266 (1995)

[19] Maxwell, J.A.: Qualitative research design. SAGE Publications Inc (2012)

[20] Nicholas, D., Herman, E.: Assessing information needs in the age of the digital consumer. Routledge (2010)

[21] Peffers, K., Tuunanen, T., Rothenberger, M.A., Chatterjee, S.: A design science research methodology for information systems research. Journal of management information systems 24(3), 45-77 (2007)

[22] Safarov, I., Meijer, A., Grimmelikhuijsen, S.: Utilization of open government data: A systematic literature review of types, conditions, effects and users. Information Polity 22(1), 1-24 (2017)

[23] Walters, W.H.: Comparative recall and precision of simple and expert searches in google scholar and eight other databases. portal: Libraries and the Academy 11(4), 971-1006 (2011)

[24] Wilson, T.D.: On user studies and information needs. Journal of documentation 37(1), 3-15 (1981)

[25] Zuiderwijk, A., Janssen, M.: Barriers and development directions for the publication and usage of open data: A socio-technical view. In: GascóHernández, M. (ed.) Open government, pp. 115-135. Springer (2014)

[26] Zuiderwijk, A., Janssen, M., Davis, C.: Innovation with open data: Essential elements of open data ecosystems. Information Polity 19(1-2), 17-33 (2014). https://doi.org/10.3233/IP-140329 